\title{
Efektifitas Implementasi Contractor Safety Management System (CSMS) Terhadap Penurunan Tingkat Kecelakaan Kerja di PT X
}

\author{
Midyana Restu Pradani ${ }^{(1, a)^{*}}$, Maya Dewi Dyah Maharani ${ }^{(1)}$, \\ dan Soehatman Ramli ${ }^{(1)}$ \\ ${ }^{(1)}$ Prodi Magister Manajemen - Manajemen Keselamatan Keselamatan Kerja dan Lingkungan, Universitas \\ Sahid \\ Email : ${ }^{\left({ }^{*}\right)}$ pmidyanarestu@gmail.com
}

Diterima (26 Maret 2021), Direvisi (Tanggal 10 Juni 2021)

\begin{abstract}
Contractor Safety Management System (CSMS) is a documentation of a control mechanism in the form of guidelines to ensure business standards in managing HSE performance of contractors. PT X is a company engaged in services in the oil and gas sector which has a high risk in every day-to-day operational activity of having an accident with lost working hours (LTI) caused by contractors. This study aims to determine whether the CSMS implementation is effective enough to reduce the level of accidents at PT X. This research is a descriptive type of research or a qualitative approach evaluation study with the method of data analysis carried out by the Literature Tracing Method which produces CSMS Implementation Data \& Accident Data and interviews. experts, then structured CSMS problems into hierarchical institutional elements and sub-elements using the Interpretative Structural Modeling (ISM) Method. The results showed that the implementation of CSMS at PT X was quite effective in reducing the number of accidents at PT X which can be seen from the results of the achievement of the Lagging Indicators there is no work accident due to the contractor and the implementation of the Leading Indicators carried out by PT X and its contractors but if it is better but for the implementation of this CSMS cycle must be carried out according to the CSMS guidelines at PT X and with consistency at each stage so that there were no negligence that impacted accidents for contractors carry out contract work at PT X.
\end{abstract}

Keywords: Contractor, CSMS

Abstrak. Contractor Safety Management System (CSMS) adalah merupakan pendokumentasian suatu mekanisme kontrol dalam bentuk panduan untuk menjamin standar usaha dalam pengelolaan kinerja HSE dari para kontraktor. PT X adalah salah satu perusahaan yang bergerak dibidang jasa services di bidang minyak dan gas bumi memiliki resiko tinggi dalam setiap kegiatan operasional sehari-hari pernah mengalami kecelakaan dengan jam kerja hilang (LTI) yang diakibatkan oleh kontraktor. Penelitian ini bertujuan untuk mengetahui apakah sudah cukup efektif Implementasi CSMS terhadap penurunan tingkat kecelakaan kerja di PT X. Penelitian ini merupakan jenis penelitian deskriptif atau studi evaluasi pendekatan kualitatif dengan metode analisis data dilakukan dengan Metode Penelusuran Kepustakaan yang menghasilkan Data Implementasi CSMS \& Data Kecelakaan serta wawancara para pakar, kemudian dilakukan strukturisasi permasalahan CSMS ke dalam bentuk elemen dan sub elemen kelembagaan hierarki dengan Metode Interpretative Structural Modelling (ISM). Hasil penelitian menunjukkan bahwa Implementasi CSMS di PT $\mathrm{X}$ sudah cukup Efektif terhadap penurunan angka kecelakaan di PT X yang dilihat dari hasil pencapaian Lagging Indicators tidak ada kecelakaan kerja akibat dari kontraktor serta implementasi dari Leading Indicators yang dijalankan oleh PT X dan Kontraktornya namun jika lebih baik untuk implementasi siklus CSMS ini harus dilakukan sesuai dengan pedoman CSMS di PT X dan dengan konsistensi pada setiap tahapannya supaya tidak ada kelalaian yang berdampak kecelakaan bagi kontraktor dalam menjalankan pekerjaaan kontrak di PT X.

Kata kunci: Kontraktor, CSMS 


\section{PENDAHULUAN}

Penggunaan jasa kontraktor sering dibutuhkan untuk penunjang kegiatan suatu industri atau perusahaan. Adapun keuntungan dari penggunaan jasa kontraktor ataupun subkontraktor adalah untuk meningkatkan produktifitas dan efisiensi, menciptakan kesempatan kerja; meningkatkan skala ekonomi; transfer teknologi, mitigasi resiko; dan dukungan finansial. Pada perkembangannya, penggunaan jasa kontraktor banyak dimanfaatkan pada beberapa sektor industri misalnya industri minyak dan gas, pertambangan, pengembangan properti, perkantoran, dan industri lainnya. Pekerjaan yang diserahkan kepada perusahaan lain termasuk pembangunan sarana dan prasarana produksi maupun hunian, penyedia makanan, sistem keamanan, petugas kebersihan, pengadaan bahan kimia dan jasa pengiriman produk, dan lain-lain. Setiap pekerjaan atau pengadaan barang dan jasa memiliki tingkat potensi bahaya yang berbeda-beda, baik resiko tinggi, sedang dan rendah. Berdasarkan risikorisiko yang selalu dihadapkan oleh industri minyak dan gas, berbagai peraturan dan standar yang dikeluarkan oleh lembaga atau pemerintah, untuk dapat mencegah terjadinya kecelakaan tersebut salah satunya melalui program Contractor Safety Management System yang selanjutnya akan disebut CSMS [5].

Pada beberapa industri minyak dan gas sering kali membutuhkan jasa kontraktor untuk melakukan pekerjaan mengingat industri minyak dan gas merupakan industri yang kompleks dan sebagian besar pekerjaan dalam pekerjaan beresiko tinggi yang jika tidak ada kontrol pada pekerjaan tersebut dapat menimbulkan kecelakaan [4].

Kecelakaan adalah suatu kejadian yang terjadi di luar kontrol seseorang, dan menyebabkan terjadinya luka, bahkan kematian. Angka kecelakaan kerja di Indonesia menunjukkan tren yang meningkat. Pada tahun 2017 angka kecelakaan kerja yang dilaporkan sebanyak 123.041 kasus, sementara itu sepanjang tahun 2018 mencapai 173.105 kasus [1].

PT X adalah salah satu perusahaan yang bergerak dibidang jasa services di bidang minyak dan gas bumi memiliki resiko tinggi dalam setiap kegiatan operasional sehari-hari. Tidak semua pekerjaan dilakukan sendiri oleh perusahaan namun lebih banyak pekerjaan tersebut akan dibantu oleh kontraktor. Sudah menjadi tanggung jawab perusahaan dalam membina kontraktor yang bekerja dengan perusahaan dan agar dapat menerapkan K3 guna mencegah kecelakaan dan kerugian perusahaan.

Peningkatan penggunaan tenaga kontraktor dalam Bisnis PT $\mathrm{X}$ inilah yang mengharuskan adanya peningkatan partnerships dan teamwork antara pemberi kerja dan kontraktor. Tahun 2018 merupakan tahun dimana PT X mengalami kecelakaan dengan jam kerja hilang (LTI) yang diakibatkan oleh kontraktor. Dari kejadian dan fenomena kecelakaan yang terjadi pada saat pelaksanaan proyek terdapat perbaikan terhadap sistem manajemen yaitu CSMS (Contractor Safety Management System), dimana program tersebut digunakan untuk mengelola keselamatan kerja para kontraktor.

Melihat kondisi tersebut, PT X kemudian berusaha membuat suatu strategi untuk memperbaiki HSE Performance, sehingga di tahun 2018 dimulailah implementasi CSMS (Contractor Safety Management System) di lingkungan PT X.

Tiga tahun setelah CSMS diterapkan (2018-2020) justru berkebalikan dengan sebelum diterapkan implementasi CSMS. Mengamati fenomena tersebut, kemudian peneliti merasa perlu melakukan suatu 
kajian akademis berupa penelitian menyangkut efektifitas implementasi CSMS tersebut karena masih terdapat kecelakaan kerja di perusahaan walaupun perusahaan sudah menjalankan CSMS, maka atas dasar itulah dilakukan penelitian ini untuk mengetahui efektifitas implementasi CSMS terhadap penurunan tingkat kecelakaan kerja di Perusahaan.

Salah satu upaya untuk mengatasi berbagai permasalahan tersebut adalah dengan penguatan internal perusahaan khususnya di Tim CSMS. Tim CSMS dalam hal ini diharapkan mampu memberikan jawaban atas permasalahan diatas. Sehingga diperlukan suatu strategi yang tepat guna menguatkan implementasi CSMS agar dapat menurunkan angka kecelakaan di perusahaan. Agar penelitian lebih terukur dan terarah, digunakan suatu alat analisis (tools) berupa Interpretative Structural Modelling (ISM). Dimana ISM adalah alat analisis yang digunakan untuk mengetahui elemen dan sub elemen kunci dalam program penguatan implementasi siklus CSMS.

Salah satu teknik pemodelan yang dikembangkan untuk merencanakan kebijakan strategis adalah Interpretative Structural Modeling (ISM). ISM adalah suatu teknik yang digunakan untuk membantu menentukan urutan tujuan pada hubungan yang kompleks, menemukan subelemen kunci, karakter setiap sub elemen dan memberikan gambaran yang konkrit tentang suatu struktur hierarki melalui pendapat para ahli. Proses ISM mengubah model yang tidak jelas, sistem yang buruk menjadi model yang terlihat dan terdefinisi dengan baik [9].

Tiga hal yang dihasilkan oleh metode ISM tersebut meliputi: (1) elemen kunci, (2) struktur hirarki elemen, dan (3) pengelompokan elemen dalam empat sektor klasifikasi. Keempat sektor klasifikasi tersebut adalah sektor I atau independent, sektor II atau linkage, sektor III atau dependent, dan sektor IV atau autonomous. Klasifikasi sektor independent adalah elemen yang memiliki kekuatan penggerak besar, dan kecil ketergantungannya. Klasifikasi sektor linkage adalah sektor yang memiliki hubungan antar peubah yang tidak stabil dan setiap perubahan tindakan dari peubah tersebut akan berdampak terhadap sub-elemen lainnya. Umpan balik dari pengaruhnya dapat memperbesar dampak, sehingga sub-elemen ini harus dikaji secara hati-hati. Klasifikasi sektor dependent adalah sub-elemen yang tidak bebas. Sedangkan, klasifikasi sektor autonomus merupakan subelemen yang tidak terkait langsung dengan sistem, dan memiliki hubungan yang sedikit, tetapi dapat lebih kuat berpengaruh terhadap pencapaian tujuan [3].

Berdasarkan dari latar belakang diatas maka penulis tertarik melakukan penelitian mengenai Analisis efektifitas Implementasi Contractor Safety Management System (CSMS) terhadap penurunan tingkat kecelakaan kerja di PT $\mathrm{X}$.

\section{METODE PENELITIAN}

Lokasi penelitian ini di PT X dengan alamat J1. Medan Merdeka Selatan No. 17, Gambir Jakarta Pusat. Pelaksanaan penelitian ini dilaksanakan November 2020 - Januari 2021. Penelitian ini menggunakan jenis penelitian deskriptif atau studi evaluasi pendekatan kualitatif. Penelitian ini bertujuan untuk menemukan fakta-fakta di lapangan yang akan menghasilkan interpertasi yang tepat, akurat serta akan melukiskan efektifitas Implementasi CSMS terhadap penurunan tingkat kecelakaan.

Dalam penelitian menggunakan informan kunci. Informan kunci adalah personil dimana akan didapatkan pandangan untuk memperoleh informasi dari sekelompok orang yang terbatas jumlahnya [2]. Informan kunci juga dapat 
diartikan sebagai informan awal yaitu memilih orang yang bisa mengenali secara keseluruhan medan secara luas dan tergolong informan yang cerdas [10].

Data yang diperoleh dan dikumpulkan dalam penelitian ini bersumber dari data primer dan data sekunder. Data Primer didapatkan dari hasil wawancara mendalam (indepth interview) dengan dengan pihak pihak yang berhubungan dengan pengelolaan CSMS di PT X dan Pendapat pakar (expert judgement) khususnya dalam mendapatkan tujuan dan kendala dari implementasi CSMS di PT X, penentuan elemen kunci tujuan dan kendala serta penilaian bobot terhadap kriteria dan alternatif strategi penguatan implementasi CSMS di PT X, sedangkan Data Sekunder merupakan data-data yang telah ada seperti data implementasi CSMS dan data kecelakaan kerja di PT X bagi kontraktor dengan pekerjaan Risiko Rendah - Risiko Menengah - Risiko Tinggi, selanjutnya dilakukan proses analisa dan interpretasi terhadap data-data tersebut sesuai dengan tujuan penelitian.

Dalam penelitian ini, penentuan pakar sebagai responden penelitian dilakukan dengan menggunakan Metode Purposive Sampling, dimana penentuan pakar dilakukan berdasarkan kriteria-kriteria kepakaran antara lain: 1) Latar belakang harus sesuai dengan fokus penelitian; 2) Memiliki pengalaman lebih dari 10 tahun pada masing-masing profesi; 3) Memiliki sikap profesionalitas dan komitmen terhadap profesi yang ditekuni. Selain kepakaran yang dikuasai, pemilihan responden juga didasari atas keterwakilan dari lembaga atau institusi yang tidak lain juga merupakan stakeholder pada penelitian ini. Jumlah pakar dalam penelitian ini berjumlah 4 pakar diantaranya mereka mempunyai peranan penting dalam Tim CSMS PT X yaitu Ketua I, Ketua II dan Anggota Tim CSMS PT X.
Variabel bebas dalam penelitian ini adalah Implementasi CSMS. Sedangkan variabel terikat dalam penelitian ini adalah Angka Kecelakaan yang didapatkan dari Data HSE Performance PT X.

Metode Analisis data dilakukan dengan Metode Penelusuran Kepustakaan yang menghasilkan Data Implementasi CSMS \& Data Kecelakaan di PT X bagi kontraktor dengan pekerjaan Risiko Rendah - Risiko Menengah - Risiko Tinggi, selanjutnya dilakukan identifikasi permasalahan-permasalahan pada saat implementasi CSMS dengan menggunakan wawancara para pakar, kemudian selanjutnya dilakukan strukturisasi permasalahan tim CSMS ke dalam bentuk elemen dan sub elemen kelembagaan hierarki dengan Metode Interpretative Structural Modelling (ISM).

\section{HASIL DAN PEMBAHASAN}

Implementasi CSMS yang diterapkan oleh PT X berdasarkan Pedoman CSMS No. A-003-PDC-2018-S0 Revisi ke-00 dan TKO CSMS No. B-034/PDC/2019-S9 terbagi menjadi dua fase yaitu Fase Administratif dan Fase Implementasi yang mana dari masing masing fase mempunyai 3 (tiga) tahapan, yaitu pada Fase Administratif mempunyai tahapan yaitu Penilaian Risiko, Pra Kualifikasi dan Seleksi sedangkan pada Fase Implementasi dimulai dari tahapan Pre Job Activity, Work In Progress dan Final Evaluation [7].

Kedua Sistem Tata Kelola yang disebutkan diatas adalah Prosedur penerapan CSMS yang dijadikan acuan PT $\mathrm{X}$ dalam mengelola aspek HSE untuk pengadaan barang dan jasa yang diberikan kepada mitra kerja PT X.

Berdasarkan data yang diperoleh dari bagian QHSSE di PT X diketahui bahwa total perusahaan yang bekerja sama dengan 
PT X berdasarkan kategorinya adalah sebagai berikut :

Tabel 1. Total Perusahaan yang terlibat kontrak dengan PT X beserta Kategori Risiko

\begin{tabular}{|c|c|c|}
\hline No & Kategori & Jumlah \\
\hline 1. & Risiko Tinggi (High Risk) & 27 \\
\hline 2. & $\begin{array}{l}\text { Risiko Menengah (Medium } \\
\text { Risk) }\end{array}$ & 8 \\
\hline 3. & Risiko Rendah (Low Risk) & 5 \\
\hline Tota & & 40 \\
\hline
\end{tabular}

Sedangkan berdasarkan hasil laporan Self Declare CSMS pada Triwulan III tahun 2020 ke SubHolding Upstream disimpulkan secara kuantitatif pencapaian implementasi CSMS PT X adalah sebagai berikut:

Tabel 2. Laporan Self Declare CSMS pada Triwulan III tahun 2020 PT X ke SubHolding Upstream

\begin{tabular}{|c|c|c|c|c|}
\hline No & $\begin{array}{l}\text { Tahapan } \\
\text { CSMS }\end{array}$ & $\begin{array}{c}\text { Jumlah } \\
\text { Kontrak } \\
\text { tor }\end{array}$ & $\begin{array}{c}\text { Penc } \\
\text { apai } \\
\text { an }\end{array}$ & $\begin{array}{c}\text { Pencap } \\
\text { aian } \\
\text { Score }\end{array}$ \\
\hline 1 & $\begin{array}{c}\text { Risk } \\
\text { Assessment }\end{array}$ & \multirow{6}{*}{$\begin{array}{c}40 \\
\text { Kontrakt } \\
\text { or }\end{array}$} & 2 & $5 \%$ \\
\hline 2 & $\begin{array}{c}\text { Pra } \\
\text { Kualifikasi }\end{array}$ & & 20 & $50 \%$ \\
\hline 3 & Seleksi & & 2 & $5 \%$ \\
\hline 4 & $\begin{array}{l}\text { Pre Job } \\
\text { Activity }\end{array}$ & & 6 & $15 \%$ \\
\hline 5 & $\begin{array}{l}\text { Work In } \\
\text { Progress }\end{array}$ & & 3 & $8 \%$ \\
\hline 6 & $\begin{array}{c}\text { Final } \\
\text { Evaluation }\end{array}$ & & 3 & $8 \%$ \\
\hline \multicolumn{4}{|c|}{$\begin{array}{c}\text { Total Pencapaian Score siklus } \\
\text { CSMS }\end{array}$} & $15 \%$ \\
\hline
\end{tabular}

Berdasarkan pada cakupan Laporan Self Declare CSMS pada Triwulan III tahun 2020 PT X ke SubHolding Upstream bahwa implementasi siklus CSMS di PT X masih belum berjalan dengan baik.

Peneliti melakukan Analisis Efektifitas Implementasi Contractor Safety Management System (CSMS) terhadap penurunan tingkat kecelakaan kerja di PT X sesuai dengan hasil analisa Data CSMS di PT X sesuai dengan Pedoman CSMS No. A-003-PDC-2018 dengan membandingkan implementasi CSMS di PT X didapatkan hasil sebagai berikut : [6]

Dari 2 fase implementasi CSMS yang terdiri dari 6 tahapan CSMS yang sudah berjalan dengan baik namun belum konsisten antara lain Pra Kualifikasi, Pre Job Activity, Work In Progress dan Final Evaluation. Sedangkan untuk tahapan Risk Assessment dan Seleksi perlu dilakukan perbaikan supaya dapat berjalan dengan baik.

Tingkat penerapan CSMS dapat diketahui dengan melihat pencapaian HSE Performance Indicator. Penilaian tersebut berfungsi untuk melihat performance HSE kontraktor selama melaksanakan pekerjaan.

Pada tahun 2018 di PT X terjadi satu kecelakaan kerja pada kontraktor. Terjadinya kecelakaan kerja erat kaitannya dengan pencapaian HSE Performance Indicator PT X. Oleh karena itu PT X langsung menerapkan sistem berupa Contractor Safety Management System (CSMS) hal tersebut berguna untuk mengurangi angka kecelakaan kerja serta melakukan pencegahan kecelakaan kerja dengan tepat agar dapat menciptakan lingkungan kerja yang aman, nyaman, efisien, dan produktif.

Sedangkan berdasarkan hasil laporan Number of Recordable Accident \& TRIR PT X tahun 2015-2020 disimpulkan secara kuantitatif pencapaian HSE Performance PT X adalah sebagai berikut : 
Midyana Restu Pradani : Efektifitas Implementasi Contractor Safety Management System (CSMS)

Terhadap Penurunan Tingkat Kecelakaan Kerja di PT X

Jurnal Migasian, e-issn: 2615-6695 / p-issn: 2580-5258

Tabel 3. Number of Recordable Accident \& TRIR PT X tahun 2015-2020

\begin{tabular}{|l|c|c|c|c|c|c|}
\hline $\begin{array}{c}\text { Number of } \\
\text { Recordable Accident } \\
\text { \& TRIR PT X }\end{array}$ & $\mathbf{2 0 1 5}$ & $\mathbf{2 0 1 6}$ & $\mathbf{2 0 1 7}$ & $\mathbf{2 0 1 8}$ & $\mathbf{2 0 1 9}$ & $\mathbf{2 0 2 0}$ \\
\cline { 2 - 7 } & 3 & 3 & 0 & 1 & 3 & 5 \\
\hline Total Recordable Incident & 3 & 0.97 & 0.00 & 0.22 & 0.26 & 0.36 \\
\hline $\begin{array}{l}\text { No.of Total Recordable } \\
\text { Incident Rate (TRIR) }\end{array}$ & 1.73 & 2 & 1.88 & 1.79 & 1.61 & 1.45 \\
\hline TRIR (TRIR Platform) & 1.7 & 2 &
\end{tabular}

Sumber : HSE Performance PT X ytd Oktober 2020

Berdasarkan pada cakupan Laporan Number of Recordable Accident \& TRIR PT X bahwa pencapaian HSE Performance PT $X$ masih fluktuatif terkadang angka statistik kecelakaaan kerja dari tahun ke tahun turun dan naik namun memberikan kontribusi terhadap statistik dari Kontraktor adalah di tahun 2018. Selain itu kecelakaan terjadi di internal PT $\mathrm{X}$ dan dari tahun 2015-2020 masih fluktuatif. Hal ini perlu dibahas lebih lanjut untuk angka secara keseluruhan masih dibawah TRIR Platform setiap tahunnya. Namun dari keseluruhan Recordable Incident di PT X bahwa salah satu yang kejadian kecelakaan yang ada di PT $X$ di luar angka kontribusi dari kontraktor itu sendiri.

Peneliti melakukan Analisis Efektifitas Implementasi Contractor Safety Management System (CSMS) terhadap penurunan tingkat kecelakaan kerja di PT X sesuai dengan hasil analisa Data CSMS di PT X sesuai dengan Pedoman CSMS No. A-003-PDC-2018 dan TKO CSMS No. B034/PDC/2019-S9 dengan membandingkan implementasi CSMS dan HSE Performance di PT $\mathrm{X}$ didapatkan hasil sebagai berikut [6\&7]:

1. Dari 2 fase implementasi CSMS yang terdiri dari 6 tahapan CSMS yang sudah berjalan namun belum konsisten antara lain Pra Kualifikasi, Pre Job Activity, Work In Progress dan Final Evaluation. Sedangkan untuk tahapan Risk Assessment dan Seleksi perlu dilakukan perbaikan supaya dapat berjalan dengan baik.
2. Pencapaian HSE Performance PT $X$ masih fluktuatif terkadang angka statistik kecelakaaan kerja dari tahun ke tahun turun dan naik namun secara keseluruhan masih dibawah TRIR Platform setiap tahunnya.

3. Kejadian kecelakaan yang terjadi pada kontraktor dan memberikan kontribusi pada HSE Performance PT $X$ adalah tahun 2018, namun dari tahun 2018 sampai dengan Oktober 2020 tidak ada kecelakaan yang berasal dari kontraktor. Yang dimana tahun implementasi CSMS pertama kali di PT X adalah pada tahun 2018.

Dengan demikian Implementasi CSMS di PT X sudah cukup Efektif terhadap penurunan angka kecelakaan di PT $\mathrm{X}$, namun untuk implementasi siklus CSMS ini harus dilakukan sesuai dengan pedoman CSMS di PT X dan dengan konsistensi pada setiap tahapannya supaya tidak ada kelalaian yang berdampak kecelakaan bagi kontraktor dalam menjalankan pekerjaaan kontrak di PT X dan berdasarkan hasil analisis ISM yang dilakukan, diperoleh bahwa sub-elemen yang disertakan dari kedua elemen, yaitu: (1) tujuan, dan (2) kendala, tidak ditemukan sub-elemen yang termasuk dalam klasifikasi autonomous. Hal ini menunjukkan bahwa kedua elemen dan sub-elemen yang disertakan tersebut merupakan elemen yang dekat dan saling terkait dalam program Implementasi CSMS terhadap penurunan angka kecelakaan di PT $X$. Hal ini terutama adalah karena elemenelemen tersebut mempunyai driving power atau daya dorong terhadap keberhasilan program.

Dalam penelitian ini peneliti menggunakan konsep pengelolaan data dengan metode ISM dengan merujuk konsep Saxena (1992) program kemudian dapat dibagi ke dalam sembilan elemen, yaitu: (1) sektor masyarakat yang terpengaruh oleh program, (2) kebutuhan 
dari program, (3) kendala utama program, (4) perubahan yang dimungkinkan dalam program, (5) tujuan dari program, (6) tolok ukur untuk menilai setiap tujuan program, (7) aktivitas yang dibutuhkan guna perencanaan tindakan, (8) ukuran aktivitas guna mengevaluasi hasil yang dicapai oleh setiap aktivitas, dan (9) lembaga yang terlibat dalam pelaksanaan program [8]. Dengan merujuk kepada konsep tersebut, maka implementasi CSMS terhadap penurunan angka kecelakaan di PT X dirancang dengan 2 elemen yaitu (1) Tujuan CSMS dan (2) Kendala CSMS.

Peneliti menggunakan software ISM Profesional 2.0 yang merupakan aplikasi berbasis website.

Elemen Tujuan terdiri dari sub elemen pada tabel berikut:

Tabel 4. Sub Elemen dari Elemen Tujuan [6]

\begin{tabular}{|c|c|}
\hline $\begin{array}{l}\text { Variabel } \\
\text { i }\end{array}$ & Sub Elemen \\
\hline $\mathrm{A}_{1}$ & $\begin{array}{lr}\text { Keseragaman } & \text { pedoman } \\
\text { pengelolaan HSE } & \text { bagi } \\
\text { kontraktor untuk } & \text { seluruh } \\
\text { kegiatan perusahaan } & \\
\end{array}$ \\
\hline $\mathrm{A}_{2}$ & $\begin{array}{l}\text { Menjamin operasi unit Bisnis di } \\
\text { PT X yang berkaitan dengan } \\
\text { bidang usaha EPC, Labor } \\
\text { Supply, Heavy Transport } \\
\text { Equipment, } \\
\text { Maintenance, Marine Services } \\
\text { dan Catering Services berjalan } \\
\text { dengan aman untuk mendukung } \\
\text { tercapainya target yang telah } \\
\text { ditetapkan }\end{array}$ \\
\hline $\mathrm{A}_{3}$ & $\begin{array}{lr}\text { Meningkatkan } & \text { kemampuan } \\
\text { kontraktor lokal dalam } & \text { lon } \\
\text { menghadapi persaingan global }\end{array}$ \\
\hline $\mathrm{A}_{4}$ & $\begin{array}{l}\text { Menjamin keselamatan dan } \\
\text { Kesehatan Kerja para pekerja } \\
\text { kontraktor }\end{array}$ \\
\hline $\mathrm{A}_{5}$ & $\begin{array}{l}\text { Mencegah terjadinya kerugian } \\
\text { material, peralatan dan } \\
\text { kerusakan lingkungan }\end{array}$ \\
\hline $\mathrm{A}_{6}$ & $\begin{array}{l}\text { Menjaga dan meningkatkan citra } \\
\text { perusahaan }\end{array}$ \\
\hline $\mathrm{A}_{7}$ & Mengurangi/menghilangkan \\
\hline
\end{tabular}

\begin{tabular}{|c|c|}
\hline & $\begin{array}{l}\text { dampak negatif terhadap aspek } \\
\text { HSE untuk mencegah kerugian } \\
\text { perusahaan }\end{array}$ \\
\hline $\mathrm{A}_{8}$ & \begin{tabular}{lcc}
\multicolumn{2}{l}{ Meningkatkan } & \multicolumn{2}{l}{ kepedulian } & dan \\
kesadaran & kontraktor & dalam \\
pengelolaan & aspek & HSE, \\
sehingga & insiden & yang \\
disebabkan & kontraktor & dapat \\
dihilangkan & & \\
\end{tabular} \\
\hline $\mathrm{A}_{9}$ & 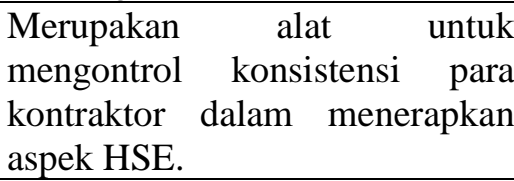 \\
\hline
\end{tabular}

Elemen kendala terdiri dari sub elemen pada tabel berikut:

Tabel 5. Sub Elemen dari Elemen Kendala

\begin{tabular}{|c|l|}
\hline $\begin{array}{c}\text { Variabel } \\
\mathbf{j}\end{array}$ & \multicolumn{1}{|c|}{ Sub Elemen } \\
\hline $\mathrm{A}_{1}$ & $\begin{array}{l}\text { Pedoman CSMS yang belum } \\
\text { dapat digunakan untuk } \\
\text { seluruh unit bisnis di PT X }\end{array}$ \\
\hline $\mathrm{A}_{2}$ & $\begin{array}{l}\text { Masih ada karyawan dan tim } \\
\text { CSMS yang belum paham } \\
\text { tentang pedoman CSMS }\end{array}$ \\
\hline $\mathrm{A}_{3}$ & $\begin{array}{l}\text { Kurangnya Komitmen } \\
\text { Manajemen Kontraktor dalam } \\
\text { menjalankan Sistem } \\
\text { Manajemen HSE }\end{array}$ \\
\hline $\mathrm{A}_{4}$ & $\begin{array}{l}\text { Jadwal dari setiap tim CSMS } \\
\text { yang tidak dapat selaras } \\
\text { mengakibatkan penundaan } \\
\text { pelaksanaan verifikasi /audit } \\
\text { setiap komponen CSMS }\end{array}$ \\
\hline $\mathrm{A}_{5}$ & $\begin{array}{l}\text { Pemahaman setiap kontraktor } \\
\text { tidak sama }\end{array}$ \\
\hline $\mathrm{A}_{6}$ & $\begin{array}{l}\text { Calon Kontraktor Potensial } \\
\text { yang tidak memenuhi } \\
\text { persyaratan prakualifikasi } \\
\text { CSMS }\end{array}$ \\
\hline $\mathrm{A}_{7}$ & $\begin{array}{l}\text { Kepedulian dan kesadaran } \\
\text { kontraktor masih rendah }\end{array}$ \\
\hline $\mathrm{A}_{8}$ & $\begin{array}{l}\text { Tidak konsisten pelaksanaan } \\
\text { siklus CSMS kepada seluruh } \\
\text { kontraktor yang mempunyai } \\
\text { kontrak Kerjasama dengan PT } \\
\text { X }\end{array}$ \\
\hline Keterlambatan informasi yang \\
\hline
\end{tabular}


Midyana Restu Pradani : Efektifitas Implementasi Contractor Safety Management System (CSMS)

Terhadap Penurunan Tingkat Kecelakaan Kerja di PT X

Jurnal Migasian, e-issn: 2615-6695 / p-issn: 2580-5258

\begin{tabular}{|c|l|}
\hline & $\begin{array}{l}\text { diterima oleh tim CSMS } \\
\text { terkait kontrak yang sudah } \\
\text { berjalan. }\end{array}$ \\
\hline $\mathrm{A}_{10}$ & $\begin{array}{l}\text { Keterbatasan waktu dalam } \\
\text { menjalankan sebuah proyek }\end{array}$ \\
\hline
\end{tabular}

(Sumber: Hasil Wawancara Tim CSMS PT X)

\section{Elemen Tujuan}

1. Grafik Kuadran

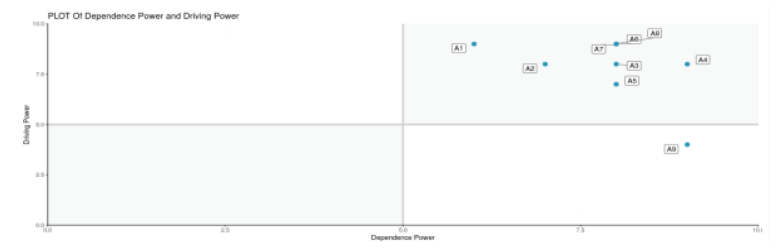

Gambar 1. Output Analisis Grafik Kuadran Elemen Tujuan

Hasil analisis menunjukkan elemen tujuan ada pada 2 (dua) kuadran yaitu kuadran linkage dan kuadran dependen. Gambar 12 menunjukkan bahwa subelemen Keseragaman pedoman pengelolaan HSE bagi kontraktor untuk seluruh kegiatan perusahaan (A1), Menjamin operasi unit Bisnis di PT $\mathrm{X}$ yang berkaitan dengan bidang usaha EPC, Labor Supply, Heavy Transport Equipment, Building Maintenance, Marine Services dan Catering Services berjalan dengan aman untuk mendukung tercapainya target yang telah ditetapkan (A2), Meningkatkan kemampuan kontraktor lokal dalam menghadapi persaingan global (A3), Menjamin keselamatan dan Kesehatan Kerja para pekerja kontraktor (A4), Mencegah terjadinya kerugian material, peralatan dan kerusakan lingkungan (A5), Menjaga dan meningkatkan citra perusahaan

Mengurangi/menghilangkan negatif terhadap aspek HSE untuk mencegah kerugian perusahaan (A7), dan meningkatkan kepedulian dan kesadaran kontraktor dalam pengelolaan aspek HSE, sehingga insiden yang disebabkan kontraktor dapat dihilangkan (A8) memiliki hubungan antar peubah yang tidak stabil atau termasuk dalam kuadran linkage. Artinya, setiap perubahan tindakan dari peubah tersebut akan berdampak terhadap sub-elemen lainnya. Sementara itu, umpan balik dari pengaruhnya dapat memperbesar dampak, sehingga sub-elemen ini harus dikaji secara hati-hati.

Analisis klasifikasi dari elemenelemen tersebut, juga menunjukkan adanya peubah tidak bebas dan terpengaruh oleh adanya program, yaitu sebagai akibat tindakan tujuan dari sub-elemen lainnya. Sub-elemen yang termasuk dalam kuadran dependent adalah Merupakan alat untuk mengontrol konsistensi para kontraktor dalam menerapkan aspek HSE (A9). Subelemen tujuan tersebut merupakan peubah tidak bebas dan akan terpengaruh oleh program sebagai akibat dari tujuan lainnya.

\section{Grafik Level}

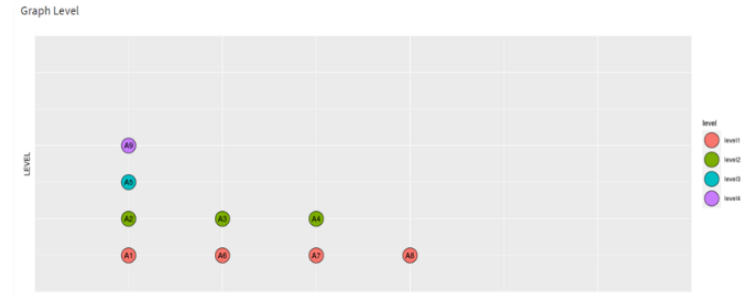

Gambar 2. Output Analisis Grafik Level Elemen Tujuan

Untuk menetapkan tujuan terbaik (tujuan kunci) ditunjukkan melalui Gambar 13 bahwa level 1 atau elemen kuncinya yaitu Keseragaman pedoman pengelolaan HSE bagi kontraktor untuk seluruh kegiatan perusahaan (A1), Menjaga dan meningkatkan citra perusahaan (A6), Mengurangi/menghilangkan dampak negatif terhadap aspek HSE untuk mencegah kerugian perusahaan (A7), dan meningkatkan kepedulian dan kesadaran kontraktor dalam pengelolaan aspek HSE, sehingga insiden yang disebabkan kontraktor dapat dihilangkan (A8). Kemudian di level 2 yaitu elemen : 
Menjamin operasi unit Bisnis di PT X yang berkaitan dengan bidang usaha EPC, Labor Supply, Heavy Transport Equipment, Building Maintenance, Marine Services dan Catering Services berjalan dengan aman untuk mendukung tercapainya target yang telah ditetapkan (A2), Meningkatkan kemampuan kontraktor lokal dalam menghadapi persaingan global (A3), Menjamin keselamatan dan Kesehatan Kerja para pekerja kontraktor (A4). Kemudian di level 3 yaitu elemen : Mencegah terjadinya kerugian material, peralatan dan kerusakan lingkungan (A5) dan di level 4 yaitu elemen : mendukung pada tujuan alat untuk mengontrol konsistensi para kontraktor dalam menerapkan aspek HSE (A9).

Kesimpulannya untuk elemen tujuan kunci untuk tercapainya efektifitas implementasi CSMS terhadap penurunan angka kecelakaan kerja di PT X yaitu Keseragaman pedoman pengelolaan HSE bagi kontraktor untuk seluruh kegiatan perusahaan (A1), Menjaga dan meningkatkan citra perusahaan (A6), Mengurangi/menghilangkan dampak negatif terhadap aspek HSE untuk mencegah kerugian perusahaan (A7), dan meningkatkan kepedulian dan kesadaran kontraktor dalam pengelolaan aspek HSE, sehingga insiden yang disebabkan kontraktor dapat dihilangkan (A8).

\section{Elemen Kendala}

\section{Grafik Kuadran}

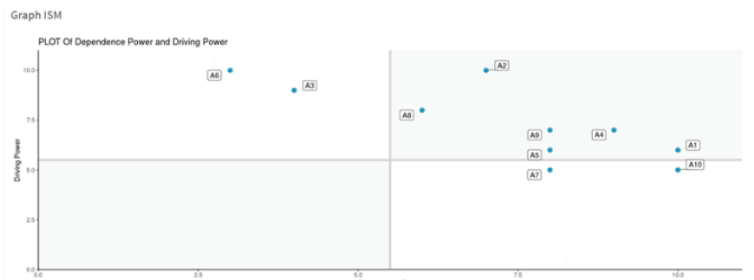

Gambar 3. Output Analisis Grafik Kuadran Elemen Kendala

Hasil analisis menunjukkan elemen kendala ada pada 3 (tiga) kuadran yaitu kuadran linkage, kuadran dependen, dan kuadran independent. Gambar 13 memperlihatkan bahwa Kepedulian dan kesadaran kontraktor masih rendah (A7) dan Keterbatasan waktu dalam menjalankan sebuah proyek (A10), termasuk kepada kuadran independent, yaitu memiliki kekuatan penggerak besar dan kecil ketergantungannya. Masih ada karyawan dan tim CSMS yang belum paham tentang pedoman CSMS (A2), Tidak konsisten pelaksanaan siklus CSMS kepada seluruh kontraktor yang mempunyai kontrak Kerjasama dengan PT $X$ (A8), Keterlambatan informasi yang diterima oleh tim CSMS terkait kontrak yang sudah berjalan (A9), Jadwal dari setiap tim CSMS yang tidak dapat selaras mengakibatkan penundaan pelaksanaan verifikasi /audit setiap komponen CSMS (A4), Pemahaman setiap kontraktor tidak sama (A5), Pedoman CSMS yang belum dapat digunakan untuk seluruh unit bisnis di PT X (A1) termasuk pada kuadran linkage. Keenam kendala tersebut perlu mendapat perhatian, karena merupakan kendala yang tidak stabil, sehingga setiap tindakan pada kendala tersebut akan memberikan dampak pada kendala lainnya, dan pengaruh umpan baliknya dapat memperbesar dampak terhadap kendala lainnya.

Adapun Calon Kontraktor Potensial yang tidak memenuhi persyaratan prakualifikasi CSMS (A6) dan Kurangnya Komitmen Manajemen Kontraktor dalam menjalankan Sistem Manajemen HSE (A3) termasuk kepada sektor dependent, dan merupakan akibat dari tindakan yang dilakukan oleh kendala kuadran linkage dan independent.

\section{Grafik Level}

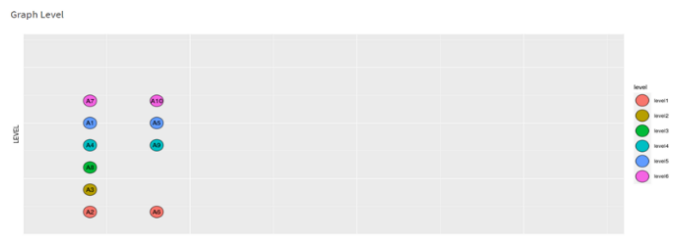

Gambar 4. Output Analisis Grafik Level Elemen Kendala 
Kendala kunci ditunjukkan melalui Gambar 13 bahwa level 1 atau elemen kuncinya yaitu pada Implementasi CSMS adalah Masih ada karyawan dan tim CSMS yang belum paham tentang pedoman CSMS (A2) dan Calon Kontraktor Potensial yang tidak memenuhi persyaratan prakualifikasi CSMS (A6). Kemudian di level 2 yaitu elemen : Kurangnya Komitmen Manajemen Kontraktor dalam menjalankan Sistem Manajemen HSE (A3) dan untuk di level 3 yaitu elemen : Tidak konsisten pelaksanaan siklus CSMS kepada seluruh kontraktor yang mempunyai kontrak Kerjasama dengan PT X (A8) di level 4 yaitu elemen : Jadwal dari setiap tim CSMS yang tidak dapat selaras mengakibatkan penundaan pelaksanaan verifikasi /audit setiap komponen CSMS (A4) dan Keterlambatan informasi yang diterima oleh tim CSMS terkait kontrak yang sudah berjalan (A9), Kemudian di level 5 yaitu elemen : Pedoman CSMS yang belum dapat digunakan untuk seluruh unit bisnis di PT X (A1) dan Pemahaman setiap kontraktor tidak sama (A5) dan yang terakhir elemen kendala di level 6 adalah karena Kepedulian dan kesadaran kontraktor masih rendah (A7) maka dari itu dibutuhkan komitmen manajemen kontraktor untuk menjalankan Sistem Manajemen HSE dan Keterbatasan waktu dalam menjalankan sebuah proyek (A10) ini tidak dapat dikendalikan karena waktu dalam menjalankan proyek tersebut sudah di atur dalam kontrak PT X dengan klien. Kondisi demikian akan menyebabkan angka kecelakaan kerja di PT X tidak dapat diturunkan, maka dari itu sebaiknya semua kendala dapat termitigasi terlebih dahulu sebelum Implementasi Siklus CSMS di suatu proyek.

Kesimpulannya untuk elemen kendala kunci untuk tercapainya efektifitas implementasi CSMS terhadap penurunan angka kecelakaan kerja di PT X yaitu
Masih ada karyawan dan tim CSMS yang belum paham tentang pedoman CSMS (A2) dan Calon Kontraktor Potensial yang tidak memenuhi persyaratan prakualifikasi CSMS (A6).

\section{KESIMPULAN}

Penerapan CSMS di PT X sudah berjalan sesuai dengan Pedoman CSMS PT $\mathrm{X}$ sesuai dengan tahapannya. Dari 2 fase implementasi CSMS yang terdiri dari 6 tahapan CSMS yang sudah berjalan namun belum konsisten antara lain Pra Kualifikasi, Pre Job Activity, Work In Progress dan Final Evaluation. Sedangkan untuk tahapan Risk Assessment dan Seleksi perlu dilakukan perbaikan supaya dapat berjalan dengan baik. Untuk Pencapaian HSE Performance PT $X$ masih fluktuatif terkadang angka statistik kecelakaaan kerja dari tahun ke tahun turun dan naik namun secara keseluruhan masih dibawah TRIR Platform setiap tahunnya dan kejadian kecelakaan yang terjadi pada kontraktor dan memberikan kontribusi pada HSE Performance PT X adalah tahun 2018, namun dari tahun 2018 sampai dengan Oktober 2020 tidak ada kecelakaan yang berasal dari kontraktor. Implementasi CSMS di PT X sudah cukup Efektif terhadap penurunan angka kecelakaan di PT $\mathrm{X}$ yang dilihat dari hasil pencapaian Lagging Indicators tidak ada kecelakaan kerja akibat dari kontraktor serta implementasi dari Leading Indicators yang dijalankan oleh PT X dan Kontraktornya namun jika lebih baik implementasi siklus CSMS ini harus dilakukan sesuai dengan pedoman CSMS di PT $\mathrm{X}$ dan dengan konsistensi pada setiap tahapannya supaya tidak ada kelalaian yang berdampak kecelakaan bagi kontraktor dalam menjalankan pekerjaaan kontrak di PT X.

Melalui penggunaan Teknik ISM telah teridentifikasi berbagai elemen yang 
terkelompokkan ke dalam dua elemen utama, yakni elemen tujuan CSMS, dan elemen kendala CSMS. Masing-masing elemen tersebut mempunyai beberapa elemen kunci diantaranya sebagai berikut :

Elemen Tujuan : Keseragaman pedoman pengelolaan HSE bagi kontraktor untuk seluruh kegiatan perusahaan, Menjaga dan meningkatkan citra perusahaan, Mengurangi/menghilangkan dampak negatif terhadap aspek HSE untuk mencegah kerugian perusahaan, dan Meningkatkan kepedulian dan kesadaran kontraktor dalam pengelolaan aspek HSE, sehingga insiden yang disebabkan kontraktor dapat dihilangkan.

Elemen Kendala : Masih ada karyawan dan tim CSMS yang belum paham tentang pedoman CSMS, dan Calon Kontraktor Potensial yang tidak memenuhi persyaratan prakualifikasi CSMS.

\section{UCAPAN TERIMAKASIH}

Penulis mengucapkan terimakasih kepada Manajemen dan Tim CSMS PT X atas izin melakukan penelitian di PT X dan kesediaannya mendampingi penulis dalam menyusun penelitian ini.

\section{DAFTAR PUSTAKA}

[1] BPJS. Angka Kecelakaan Kerja Cenderung Meningkat, BPJS Ketenagakerjaan Bayar Santunan Rp1,2 Triliun. 16 Januari. https://www.bpjsketenagakerjaan.go.id/ berita/23322/Angka-Kecelakaan-KerjaCender. 2019

[2] Madhona, Yenny Frisca. Evaluasi Penerapan Contractor Safety Management System (CSMS) Terhadap Kontraktor di PT Pertamina Refinery Unit VI Balongan. Universitas Sahid. Jakarta. 2020
[3] Maharani, Maya Dewi Dyah dan Sara, Dem Vi. Model Struktural Pengelolaan Tempat Penampungan dan Potong Ayam Secara Berkelanjutan dalam Mendukung Ketahanan Pangan. Universitas Terbuka. Jakarta. 2018

[4] OGP. Report No. 423. Safety Performance Indicator - 2010 Data. International Association of Oil \& Gas Producers. 2011

[5] Putra, Pratama S. Analisis Komitmen Manajemen pada Penerapan Contractor Safety Management System (CSMS) di PT X Tahun 2013. Universitas Indonesia. Depok. 2014

[6] PT X. Pedoman No. A-003-PDC-201820 tentang Pedoman Contractor Safety Management System (CSMS). PT X. Jakarta. 2018

[7] PT X. Tata Kerja Organisasi No. B034/PDC/2019-S9 tentang Contractor Safety Management System (CSMS). PT X. Jakarta. 2018

[8] Saxena, J. P., Sushil, \& Vrat, P. Hierarchy and Classification of Program Plan Elements Using Interpretive Structural Modeling: A Case Study of Energy Conservation in the Indian Cement Industry. System Practice, 5(6), 651-670. 1992

[9] Sushil. Interpreting the Interpretive Structural Model. Global Journal of Flexible System Management, 13 (2), 87-106. 2012.

[10] Sugiyono. Metode Penelitian Kuantitatif, Kualitatif dan $R \& D$. Bandung: Alfabeta. 2008. 